\title{
Correction to: Stem Cells in Adult Mice Ovaries Form Germ Cell Nests, Undergo Meiosis, Neo-oogenesis and Follicle Assembly on Regular Basis During Estrus Cycle
}

\author{
Diksha Sharma $^{1} \cdot$ Deepa Bhartiya $^{1}$ (D)
}

Published online: 19 October 2021

๑) Springer Science+Business Media, LLC, part of Springer Nature 2021

\section{Correction to: Stem Cell Reviews and Reports}

https://doi.org/10.1007/s12015-021-10237-4

The original version of this article unfortunately contained a mistake. The wrong Supplementary file for Supplementary file 1 was originally published with this article; it has now been replaced with the correct file.

The original article has been corrected.

Publisher's Note Springer Nature remains neutral with regard to jurisdictional claims in published maps and institutional affiliations.

The original article can be found online at https://doi.org/10.1007/ s12015-021-10237-4.

Deepa Bhartiya

bhartiyad@ nirrh.res.in

1 Stem Cell Biology Department, ICMR- National Institute for Research in Reproductive Health, Jehangir Merwanji Street, Parel, Mumbai 400 012, India 